\title{
RUMO AO X SIMPURB
}

\author{
Ana Fani Alessandri Carlos* \\ Arlete Moisés Rodrigues**
}

A geografia vive uma crise, poucos duvidam deste fato. Os sinais são vários: o preconceito contra o pensamento teórico, a recusa da crítica como fundante na construção do conhecimento, a naturalização das relações sociais trazendo como consequência o esvaziamento da história. Como consequência, a realidade destituida de sua historicidade reduz o espaço geográfico ao seu quadro físico.

Podemos, também, identificar uma crise ética como decorrência do fato de que, aos poucos, mas inexoravelmente, a universidade vem sendo invadida pelo tempo veloz da produtividade que repercute diretamente nas pesquisas cientificas e, consequentemente no processo de produção e sentido do conhecimento alí produzido. Trata-se cada vez mais produzir textos, seminários, eventos, não necessariamente conhecimento e debate.

Ciosos da necessidade sempre acrescentada, de incrementar currículos, aumenta, cada vez mais o número daqueles que não conseguindo fugir à tentação adicionam seus nomes àqueles de seus orientandos na apresentação de artigos fundados em suas teses individuais confundindo-se orientação com co-autoria. E assim, um mesmo trabalho pode ser computado triplamente no currículo de orientador - no item orientação, no item participação em eventos (mesmo que ele não tenha participado do evento), e repetido no item "produção científica". Imersos nesta lógica, é cada vez mais freqüente o número de pesquisadores que apresentam dois ou mais trabalhos num único evento; também é sintomático o aumento do número de autores assinando um mesmo trabalho ${ }^{1}$. Com isso os currículos vão ganhando tamanho, não necessariamente, conteúdo.

Mas não é só isso. Os programas de pós-graduação, submetidos aos avaliadores da CAPES, parecem "entrar numa competição" ensandecida para incrementar numericamente seus relatórios visando o aumento das notas de seus programas. É assim que a proliferação dos eventos - sem debates, apenas como vitrine para apresentação de trabalhos parecem ganhar a todos. Um novo formato de evento se impõe: um excesso de mesas redondas, mesas de comunicação, simultâneas, salas abarrotadas de painéis, etc. (os mesmos autores, com textos semelhantes, aparecem em mais de uma atividade, painéis, mesas redondas, comunicações coordenadas). Entre os presentes "um corre corre" atraz das atrações. Uma imagem de excesso revela o "conhecimento pós-moderno" fragmentado e repetitivo, para não dizer "espetacular".

O cenário acadêmico modificou-se profundamente, a "nova universidade" impõe-se pelos padrões da produtividade imerso no "produtivismo", a velocidade do tempo da chamada pós-modernidade, impõese sobre o tempo lento da reflexão. 


\section{De novo, a história do Simpurb ${ }^{2}$}

É mister lembrar que existe uma história que funda a criação dos simpósios de Geografia Urbana que se constitui como memória de uma filosofia que lhe assegura um conteúdo e lhe permite reproduzir-se, como superação a cada nova edição, sem perder o objetivo fundamental: aquele do debate aprofundado a partir de pesquisas individuais. Trata-se de um forum criado precisamente para debater a pesquisa urbana realizada no Brasil, em vários níveis a partir dos desafios que a construção de um conhecimento sobre a cidade e o urbano vai ganahando em complexidade.

O mundo moderno nos coloca diante de uma série de desafios. A reprodução da cidade e os caminhos da pesquisa urbana, realizada individualmente, coloca-nos diante de impasses que só o debate ajuda a elucidar. Nossos encontros - principalmente aqueles realizados na AGB tradicionalmente dão visibilidade a pesquisa geográfica realizada no Brasil e, por isto devem estar aberto a todos. Mas se de um lado, este critério, permite o congraçamento dos pesquisadores e dos futuros pesquisadores - o que é absolutamente fundamental para a construção da Geografia, dando visibilidade a produção geográfica brasileira, em sua mais ampla temática - que é de sua alçada; de outro lado, nem sempre têm permitido por sua magnitude, o aprofundamento de determinadas questões debatidas nas mesas redondas e que dizem respeito a temas específicos, mas não menos importantes para a compreensão da realidade. O aprofundamento destas questões caberia aos encontros temáticos de papel indiscutível para o desenvolvimento e intercâmbio da pesquisa geográfica. Assim o simpurb surge da necessidade de criação de um forum capaz de privilegiar o debate coletivo e cumulativo.

\section{A organização dos simpurbs: uma experiência importante}

Se o foco central era o debate a partir das pesquisas realizadas apontando diferenças teóricas e encadeamentos metodológicos diferenciados, fazia-se necessário privilegiar os debates; foi assim, que a cada simpósio as mesas redondas duravam 4 horas com 4 pessoas cada e jamais concomitantes entre si e a outras atividades. Foi assim que ao longo os dias de simpósio os participantes permaneciam juntos e com isso o debate de uma mesa ia fluindo para outra mesa no sentido de sua acumulação; foi assim também, que uma questão fluía de um para o outro simpósio. Também se decidiu que as pessoas presentes no simpósio permaneceriam todo o tempo criando a convivência necessária ao estabelecimento de uma reflexão coletiva.

Não havia preocupação com apresentação de trabalhos em si, mas só na medida em que propunham o debate entre diferentes. Sem estrelas nem estrelismos, todos juntos acreditando que a construção do conhecimento passava, necessariamente pela crítica, e que a crítica de idéias não se confunde com a crítica pessoal.

Assim os simpósios foram se realizando, ganhando novos desdobramentos com o debate coletivo. Foi assim que, ao longo destes anos, os simpósios trouxeram debates acalorados, apoiado na convivência de idéias absolutamente opostas, realizando "duramente" a proposta de que há várias possibilidades de pensar a cidade e o urbano e vários caminhos teóricometodológicos possíveis para "realização da pesquisa urbana" o que derrubava a idéia de uma verdade absoluta e de um método hegemônico.

A existência dos simpósios criou ao longo do tempo, o ambiente possível para o debate de idéias apoiadas no profundo 

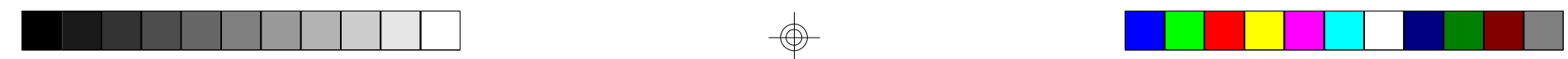

Notícias de Encontro: Rumo ao X Simpurb, pp. 207 - 210

respeito pelo exercício da diferença. Só a prática vinda da convivência permitiu a concretização

desta

possibilidade. Concretamente e, não no discurso, vinha se realizando a idéia de que a universidade é o lugar do "exercício de liberdade", lugar por excelência da realização da crítica, sem a qual não há produção de conhecimento.

Com este espírito as Comissões Científicas não aceitavam trabalhos de alunos de graduação, pois na graduação a pesquisa é um momento da formação do aluno, enquanto na pós-graduação, ela é a possibilidade da produção de "um novo conhecimento", onde se vê a pesquisa empírica potencializada através do pensamento teórico. Portanto não se tratava de "limitar participação de ninguém mas de garantir a liberdade de conseguirmos avançar no debate apronfundado sobre o sentido da cidade e do urbano no mundo moderno".

Com este espírito se construíam os temas das mesas - na realidade é possível criar uma lista imensa de temas que resvalam o urbano, não se tratava disto, mas de pensar quais os temas que efetivamente traduzem a essência da explicitação do fenômeno urbano de modo a permitir um entendimento profundo dos processos produtores da cidade e do urbano. Era isto que criava a universalidade da temática e fazia a reflexão avançar, caso contrário mergulharíamos nas fragmentações, nos estudos de caso.

O trabalho acadêmico envolve, a crítica conseqüente, baseada na realidade, desenvolvida com o espírito da superação das situações reais, visando o futuro - a realização dos simpósios foram sempre uma tarefa coletiva e feita para a coletividade de geógrafos. Essa atitude foi fundamental para gerar avanços e cada edição do cada edição surge de uma avaliação da anterior.

$$
\text { Portanto os Simpubs se }
$$

diferenciaram dos outros encontros e simpósios; nem melhor, nem pior, apenas diferente e necessário.

\section{A plenária do IX simpurb}

Ao cabo de cada Simpurb uma plenária decide a forma do próximo a partir da crítica ao que se encera, e o que vem se constatando é que se tem ganho cada vez mais adesões o que vem sinalizando mudanças. Por mais que estávamos preparados para o fato de que o simpurb tomava vôo próprio com o aumento de sua importância e tamanho, não estavamos preparados para o que aconteceu em Manaus.

Ao contrário das 8 edições anteriores, no início dos trabalhos no IX Simpurb instalou-se um "marketing" por parte dos representantes de Santa Catarina, para que o simpurb "fosse para lá". Algo estranho pois não se trata de um simpósio itinerante, que ao cabo de 2 anos muda de lugar -trata-se de uma experiência diferenciada, estabelecendo uma postura diferenciada. Embora a cada 2 anos o Simpurb seja realizado num lugar do Brasil, nunca houve, antes, nenhum movimento de lista para adesão e marketing como foi verificado em Manaus. Nada em contrário que desde o início houvesse manifestação de interesse no sentido da organização do X Simpurb, o que demonstraria o interesse no debate sobre o urbano. Mas a coleta de assinaturas já na abertura caracterizou-se pela mudança aleatória de rumo em relação à sua estrutura e, fundamentalmente de sentido do simpurb.

A estrutura do IX Simpurb já apontava mudanças pela existência de mesas redondas simultâneas com duas horas de duração, impediando o acompanhamento dos debates possíveis como desdobramentos do tema geral do evento. Ou se acompanhava o debate numa mesa 

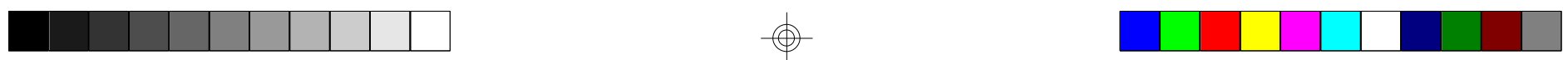

ou na outra. As apresentações eram muito rápidas e os debates exíguos. A abertura e o encerramento foram realizados por pesquisadores "de fora" do tema, revelando falta de sintonia com os Simpurbs anteriores.

Ao final da plenária, a apresentação das propostas sobre a organização do $X$ SIMPURB, selou as mudanças. A primeira proposta (sinalizada com o material distribuído por Florianópolis para "angariar os votos na plenária") apoiava-se na argumentação de que "era preciso atender, com o X Simpurb, à demanda" (seja lá o que isto quer dizer) e de que "Floripa tinha 100 praias, boa infra estrutura para receber os geógrafos e festas em outubro, pois ninguém é de ferro". Tal postura estava na contramão de tudo que havíamos construído em anos de simpurbs. Era também a primeira vez que um grupo desvinculado da pesquisa urbana encaminhava uma proposta de organização do simpurb. Com outra postura, Brasília apresentou sua proposta de realização do $X$ SIMPURB apoiada em argumentos acadêmicos. Qual não foi nossa surpresa quando a votação, realizada democraticamente, apontou na direção da realização do X SIMPURB em Florianópolis, sinalizando, inequivocamente para a "espetacularização da geografia" e, com isso, "escancarando a crise".

A geografia que se faz na UFSC tem uma história de excelência incontestável, uma simples menção a sua reputação acadêmica, seria suficiente para fundamentar a realização do simpurb em Florianópolis, o que infelizmente, não ocorreu.

\section{Notas}

1 Mas, o que é mais grave, é a exigência de algumas faculdades, para que o nome do orientador conste dos trabalhos apresentados por seus alunos para a aliberação de verbas.
2 Em 2001 publiquei no Boletim da AGB Nacional o texto "A HISTÓRIA DE UM SIMPóSIO", sobre o VII SIMPURB. 